\title{
Elevated Red Blood Cell Distribution Width Is Associated with Higher Recourse to Coronary Artery Bypass Graft
}

\author{
Georges Ephrem $^{\mathrm{a}} \quad$ Yumiko Kanei $^{\mathrm{b}}$ \\ ${ }^{a}$ Department of Cardiovascular Disease, North Shore - LIJ Health System, Manhasset, N.Y., and bivision of \\ Cardiovascular Disease, Beth Israel Medical Center, New York, N.Y., USA
}

For editorial comment see p. 133

\section{Key Words \\ Coronary bypass $\cdot$ Red blood cell width}

\begin{abstract}
Background: Red blood cell distribution width (RDW) is a measure of heterogeneity in erythrocyte size used in the differential diagnosis of anemia. High levels are associated with elevated cardiovascular biomarkers and increased mortality. The hypothesis of this study is that high RDW levels on admission are associated with higher recourse to coronary artery bypass graft (CABG) in unstable angina (UA) or non-STelevation myocardial infarction (NSTEMI) patients. Methods: An observational, cross-sectional study of all adult patients undergoing coronary angiography admitted to an urban tertiary care center in 2007 with UA or NSTEMI was conducted. Data was gathered by review of inpatient charts. RDW was considered 'high' if it exceeded the 95th percentile (16.3\%). Results: Among the 503 subjects included in the analysis, high RDW was independently associated with higher recourse to $C A B G$ versus a nonsurgical approach [OR = 2.39 (1.04-5.50); $p=0.041$ ] but not with conservative management $[\mathrm{OR}=0.97(0.51-1.84) ; \mathrm{p}=0.922]$ or percutaneous coronary intervention $[O R=0.67(0.36-1.25) ; p=0.208]$. Conclusions: This study of patients with UA or NSTEMI demon-
\end{abstract}

strated an independent association of elevated RDW with higher recourse to CABG. RDW should be considered in the stratification of patients presenting with UA or NSTEMI.

Copyright $\odot 2012$ S. Karger AG, Basel

\section{Background}

Red blood cell distribution width (RDW) is an objective measure of the heterogeneity in red blood cell (RBC) size (coefficient of variability of RBC volume) obtained from the RBC size distribution. Higher values reflect greater heterogeneity in cell sizes. It is automatically calculated by most hemocytometers by dividing the standard deviation of RBC volume by the mean corpuscular volume and multiplying by 100 to express the result as a percentage [1]. A cutoff value of $14 \%$ corresponds to the 95th percentile of RDW for the reference population in the Third National Health and Nutrition Examination Surveys (NHANES III) study; however, the normal range can vary based on the type of hemocytometer used $[2,3]$. Routinely reported as part of the complete blood count, it is mainly used as an auxiliary index in the differential diagnosis of anemia.

\section{KARGER}

Fax +4161306 1234

E-Mail karger@karger.ch

www.karger.com
(C) 2012 S. Karger AG, Basel

$0008-6312 / 12 / 1233-0135 \$ 38.00 / 0$

Accessible online at:

www.karger.com/crd
Georges Ephrem, MD, MS

Department of Cardiovascular Disease, North Shore - LIJ Health System

300 Community Drive

Manhasset, NY 11030 (USA)

E-Mail g.ephrem@gmail.com 
Higher levels of RDW are associated with increased mortality among patients with heart failure, myocardial infarction, coronary artery disease (CAD) or undergoing angiography [4-11]. A high RDW is also associated with elevated cardiovascular biomarkers and cardiac enzymes [12]. The goal of this project was to assess the independent relation between RDW, an inexpensive, readily available measure and the therapeutic decision adopted in unstable angina (UA) or non-ST-elevation myocardial infarction (NSTEMI) patients. The rationale for selecting this population lies in the difference of treatment algorithms between ST-elevation myocardial infarction (STEMI) that is driven by a time-sensitive emergent revascularization of a likely culprit lesion and UA/NSTEMI which, given the nature of the process at hand, can legitimately lead to any of the three therapeutic strategies [conservative medical management, percutaneous coronary intervention (PCI) or coronary artery bypass graft surgery (CABG)]. The hypothesis of this study is that high RDW levels are associated with higher recourse to CABG in this patient population.

\section{Methods}

\section{Study Population}

This observational, cross-sectional study was conducted at Beth Israel Medical Center, a tertiary care center in New York City. It included all patients aged 18 years or older, admitted to the telemetry floors between January 1 and December 31, 2007, with a diagnosis of UA or NSTEMI who underwent a coronary angiography during that admission. As the target population consisted of patients presenting with UA or NSTEMI who by hospital policy are sent to monitored beds, the choice of admission to the telemetry floors as an inclusion criterion allowed us to avoid including patients who developed cardiac complaints or complications during their inpatient stay. All patients who needed critical unit level of care, presented with STEMI, admitted to nontelemetry floors or did not require (or did not undergo) coronary angiography were excluded.

\section{Definitions}

Patients in this study presented to the medical center with chief complaints of chest pain, shortness of breath or decreased exercise tolerance for which they were admitted to the telemetry floors and underwent coronary angiography regardless of the presence or absence of electrocardiogram changes. They were divided into 2 groups: UA if they did not have detectable cardiac biomarkers (troponin I $<0.03 \mathrm{ng} / \mathrm{ml}$ ) and NSTEMI if they had a troponin I level $\geq 0.03 \mathrm{ng} / \mathrm{ml}$ without electrocardiogram changes qualifying for STEMI. End-points were the treatment strategies: medical therapy, PCI or CABG. The revascularization strategy was decided at the discretion of the treating physician. RDW level on admission was considered 'high' if it was greater than the 95th percentile per the normal interval of the institu-

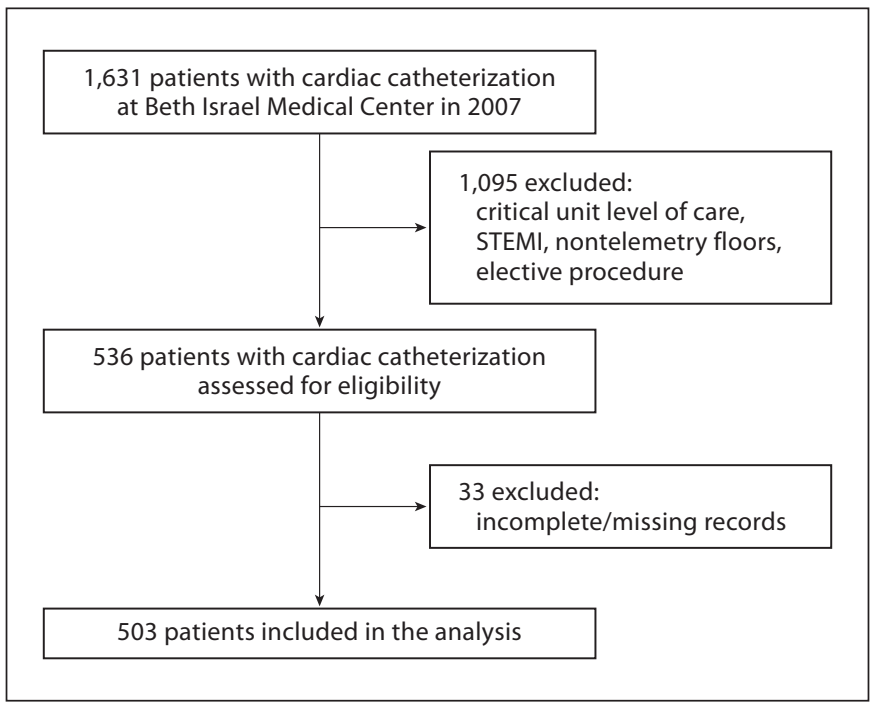

Fig. 1. Study sample selection flow diagram.

tion's laboratory (16.3\%), and 'normal' if $\leq 16.3 \%$. This grouping was based on the calibration and the reported normal range of the institution's laboratory which uses the COULTER ${ }^{\circledR}$ LH 750 Hematology Analyzer (Beckman Coulter Inc., Brea, Calif., USA).

\section{Data Collection}

Information on the subjects' demographics (age, gender and race), angiographic findings, clinical history (heart failure, CAD, hypertension, diabetes, dyslipidemia, smoking, family history of CAD, and previous CABG and stenting), laboratory measurements on admission [white blood cell count, hemoglobin, RDW, platelets, C-reactive protein (CRP), B-type natriuretic peptide (BNP) and creatinine], iron level, ferritin and total iron-binding capacity, maximal troponin I level (Tn Max), diagnosis (UA or NSTEMI) and outcomes (medical therapy, PCI or $\mathrm{CABG}$ ) was collected by conducting a retrospective chart review of all patients admitted to the hospital from January 1, 2007, until December 31, 2007, using internal electronic databases.

\section{Ethics}

The study was approved by the Beth Israel Medical Center Institutional Review Board. The requirement for obtaining informed consent was waived.

\section{Statistical Analysis}

Data were analyzed using Stata version 11.2 (StataCorp, College Station, Tex., USA). Categorical data were analyzed using $\chi^{2}$ or Fisher's exact tests. Continuous variables whose distribution followed the normality assumptions were analyzed using the Student $t$ test and ANOVA. Variables whose distribution did not approximate normality were analyzed using the nonparametric Wilcoxon rank-sum and Kruskal-Wallis tests. Multivariable logistic regression analyses were used to determine the independent 
Table 1. Characteristics of the study population overall and by each therapeutic strategy

\begin{tabular}{|c|c|c|c|c|c|}
\hline Characteristics & $\begin{array}{l}\text { Overall } \\
(\mathrm{n}=503)\end{array}$ & $\begin{array}{l}\text { Medical therapy } \\
(\mathrm{n}=270)\end{array}$ & $\begin{array}{l}\text { PCI } \\
(n=180)\end{array}$ & $\begin{array}{l}\text { CABG } \\
(n=53)\end{array}$ & $\mathrm{p}$ \\
\hline \multicolumn{6}{|l|}{ Demographics } \\
\hline Age, years & $65 \pm 13$ & $63 \pm 14$ & $68 \pm 12$ & $70 \pm 12$ & $<0.001$ \\
\hline Male & $280(56 \%)$ & $147(54 \%)$ & $101(56 \%)$ & $32(60 \%)$ & 0.721 \\
\hline Race & & & & & 0.258 \\
\hline Caucasian & $106(21 \%)$ & $52(19 \%)$ & $40(22 \%)$ & $14(26 \%)$ & \\
\hline Black & $63(13 \%)$ & $33(12 \%)$ & $24(13 \%)$ & $6(11 \%)$ & \\
\hline Hispanic & $178(35 \%)$ & $105(39 \%)$ & $55(31 \%)$ & $18(34 \%)$ & \\
\hline Asian & $40(8 \%)$ & $27(10 \%)$ & $11(6 \%)$ & $2(4 \%)$ & \\
\hline Other & $116(23 \%)$ & $53(20 \%)$ & $50(28 \%)$ & $13(25 \%)$ & \\
\hline \multicolumn{6}{|l|}{ Laboratory measurements } \\
\hline $\mathrm{WBC}, \times 1,000 / \mu \mathrm{l}$ & $8 \pm 3$ & $8 \pm 3$ & $8 \pm 2$ & $9 \pm 4$ & 0.043 \\
\hline Hemoglobin, g/dl & $13 \pm 2$ & $13 \pm 2$ & $13 \pm 2$ & $13 \pm 2$ & 0.763 \\
\hline High RDW & $101(20 \%)$ & $58(21 \%)$ & $27(15 \%)$ & $16(30 \%)$ & 0.037 \\
\hline Platelets, $\times 1,000 / \mu l$ & $244 \pm 87$ & $253 \pm 95$ & $235 \pm 66$ & $235 \pm 103$ & 0.068 \\
\hline Tn Max, ng/ml & $0.01(0.00-0.12)$ & $0.00(0.00-0.06)$ & $0.01(0.00-0.42)$ & $0.04(0.00-0.45)$ & 0.022 \\
\hline Creatinine, mg/dl & $1.0(0.8-1.3)$ & $1.0(0.8-1.3)$ & $1.1(0.9-1.3)$ & $1.1(1.0-1.8)$ & 0.025 \\
\hline Anemia & $224(45 \%)$ & $126(47 \%)$ & $75(42 \%)$ & $23(43 \%)$ & 0.570 \\
\hline Angiographic findings & & & & & $<0.001$ \\
\hline Normal or nonobstructive & & & & & \\
\hline disease & $167(33 \%)$ & $162(60 \%)$ & $5(3 \%)$ & $0(0 \%)$ & \\
\hline 1 -vessel disease & $109(22 \%)$ & $41(15 \%)$ & $62(34 \%)$ & $6(11 \%)$ & \\
\hline 2 -vessel disease & $89(18 \%)$ & $26(10 \%)$ & $52(29 \%)$ & $11(21 \%)$ & \\
\hline$\geq 3$-vessel disease & $138(27 \%)$ & $41(15 \%)$ & $61(34 \%)$ & $36(68 \%)$ & \\
\hline \multicolumn{6}{|l|}{ Medical history } \\
\hline Heart failure & $173(34 \%)$ & $97(36 \%)$ & $52(29 \%)$ & $24(45 \%)$ & 0.064 \\
\hline CAD & $287(57 \%)$ & $131(49 \%)$ & $128(71 \%)$ & $28(53 \%)$ & $<0.001$ \\
\hline HTN & $392(78 \%)$ & $203(75 \%)$ & $144(80 \%)$ & $45(85 \%)$ & 0.209 \\
\hline Diabetes & $218(43 \%)$ & $106(39 \%)$ & $86(48 \%)$ & $26(49 \%)$ & 0.137 \\
\hline Dyslipidemia & $228(45 \%)$ & $114(42 \%)$ & $94(52 \%)$ & $20(38 \%)$ & 0.057 \\
\hline Smoking & $155(31 \%)$ & $80(30 \%)$ & $53(29 \%)$ & $22(42 \%)$ & 0.204 \\
\hline $\mathrm{FHx}$ & $106(21 \%)$ & $44(16 \%)$ & $47(26 \%)$ & $15(28 \%)$ & 0.017 \\
\hline \multicolumn{6}{|l|}{ Prior interventions } \\
\hline Previous CABG & $72(14 \%)$ & $27(10 \%)$ & $43(24 \%)$ & $2(4 \%)$ & $<0.001$ \\
\hline Previous PCI & $139(28 \%)$ & $72(27 \%)$ & $57(32 \%)$ & $10(19 \%)$ & 0.163 \\
\hline Diagnosis & & & & & 0.006 \\
\hline UA & $406(81 \%)$ & $232(86 \%)$ & $134(74 \%)$ & $40(75 \%)$ & \\
\hline NSTEMI & $97(19 \%)$ & $38(14 \%)$ & $46(26 \%)$ & $13(25 \%)$ & \\
\hline
\end{tabular}

Continuous variables are reported as mean \pm standard deviation if normally distributed or median (range) if not. Categorical variables are reported as frequency (percentage). $\mathrm{p}$ values $<0.05$ are in bold. $\mathrm{WBC}=$ White blood cell count; High RDW $=$ red blood cell distribution width $>16.3 \%$; Tn Max = maximal troponin I; HTN = hypertension; FHx = family history of coronary artery disease.

associations of medical therapy alone, PCI and CABG, respectively. The multivariate models were adjusted for all the variables that were of statistical significance in the univariate and bivariate analyses for each of the endpoints of interest. Assessment for effect modifiers was performed and none were detected. Regression diagnostics and assessment of the fit of the models were conducted via the Hosmer-Lemeshow goodness of fit test which showed that they fit well. $\mathrm{p}$ values $<0.05$ were considered statistically significant.

High RDW and Recourse to CABG

\section{Results}

Among the 1,631 patients who underwent cardiac catheterization in 2007, 536 fulfilled the selection criteria. Thirty-three had incomplete or missing data and were excluded from the analysis (fig. 1). The baseline characteristics and the diagnoses of the remaining 503 subjects are listed in table 1 . On average the study popula- 
Table 2. Characteristics of the study population by RDW group $(\mathrm{n}=503)$

\begin{tabular}{|c|c|c|c|}
\hline Characteristics & $\begin{array}{l}\text { Normal RDW } \\
(\mathrm{n}=402)\end{array}$ & $\begin{array}{l}\text { High RDW } \\
(\mathrm{n}=101)\end{array}$ & $\mathrm{p}$ \\
\hline \multicolumn{4}{|l|}{ Demographics } \\
\hline Age, years & $65 \pm 13$ & $67 \pm 14$ & 0.091 \\
\hline Male & $233(58 \%)$ & $47(47 \%)$ & 0.039 \\
\hline Race & & & 0.772 \\
\hline Caucasian & $89(22 \%)$ & $17(17 \%)$ & \\
\hline Black & $48(12 \%)$ & $15(15 \%)$ & \\
\hline Hispanic & $142(35 \%)$ & $36(35 \%)$ & \\
\hline Asian & $31(8 \%)$ & $9(9 \%)$ & \\
\hline Other & $92(23 \%)$ & $24(24 \%)$ & \\
\hline \multicolumn{4}{|l|}{ Laboratory measurements } \\
\hline $\mathrm{WBC}, \times 1,000 / \mu \mathrm{l}$ & $8 \pm 3$ & $8 \pm 4$ & 0.548 \\
\hline Hemoglobin, g/dl & $13 \pm 2$ & $11 \pm 2$ & $<0.001$ \\
\hline Platelets, $\times 1,000 / \mu l$ & $240 \pm 71$ & $263 \pm 131$ & 0.017 \\
\hline Tn Max, ng/ml & $\begin{array}{l}0.01 \\
(0.00-0.10)\end{array}$ & $\begin{array}{l}0.02 \\
(0.00-0.28)\end{array}$ & 0.053 \\
\hline Creatinine, mg/dl & $1.0(0.8-1.3)$ & $1.2(0.8-1.8)$ & 0.002 \\
\hline Anemia & $146(36 \%)$ & $78(77 \%)$ & $<0.001$ \\
\hline \multirow{2}{*}{\multicolumn{3}{|c|}{$\begin{array}{l}\text { Angiographic findings } \\
\text { Normal or nonobstructive }\end{array}$}} & 0.066 \\
\hline & ive & & \\
\hline disease & $130(32 \%)$ & $37(36 \%)$ & \\
\hline 1-vessel disease & $97(24 \%)$ & $12(12 \%)$ & \\
\hline 2-vessel disease & $69(17 \%)$ & $20(20 \%)$ & \\
\hline$\geq 3$-vessel disease & $106(27 \%)$ & $32(32 \%)$ & \\
\hline \multicolumn{4}{|l|}{ Medical history } \\
\hline Heart failure & $123(31 \%)$ & $50(50 \%)$ & $<0.001$ \\
\hline CAD & $237(59 \%)$ & $50(50 \%)$ & 0.086 \\
\hline HTN & $314(78 \%)$ & $78(77 \%)$ & 0.849 \\
\hline Diabetes & $172(43 \%)$ & $46(46 \%)$ & 0.617 \\
\hline Dyslipidemia & $192(48 \%)$ & $36(36 \%)$ & 0.029 \\
\hline Smoking & $129(32 \%)$ & $26(26 \%)$ & 0.217 \\
\hline $\mathrm{FHx}$ & $94(23 \%)$ & $12(12 \%)$ & 0.011 \\
\hline \multicolumn{4}{|l|}{ Prior interventions } \\
\hline Previous CABG & $58(14 \%)$ & $14(14 \%)$ & 0.884 \\
\hline Previous PCI & $113(28 \%)$ & $26(26 \%)$ & 0.634 \\
\hline Diagnosis & & & 0.320 \\
\hline UA & $328(82 \%)$ & $78(77 \%)$ & \\
\hline NSTEMI & $74(18 \%)$ & $23(23 \%)$ & \\
\hline Treatment & & & 0.037 \\
\hline Medical therapy only & $212(53 \%)$ & $58(57 \%)$ & \\
\hline PCI & $153(38 \%)$ & $27(27 \%)$ & \\
\hline CABG & $37(9 \%)$ & $16(16 \%)$ & \\
\hline
\end{tabular}

Continuous variables are reported as mean \pm standard deviation if normally distributed or median (range) if not. Categorical variables are reported as frequency (percentage). $\mathrm{p}$ values $<0.05$ are in bold. $\mathrm{WBC}=$ White blood cell count; Tn Max $=$ maximal troponin I; HTN = hypertension; FHx = family history of coronary artery disease. tion was 65 years of age and had a high prevalence of comorbidities. Fifty-six percent $(\mathrm{n}=280)$ were male, $28 \%$ $(\mathrm{n}=139)$ had a prior stent placed and $14 \%(\mathrm{n}=72)$ had prior CABG. Baseline laboratory analysis showed normal white blood cell count $\left(8 \pm 3 \times 10^{3} / \mu \mathrm{l}\right)$, hemoglobin (13 $\pm 2 \mathrm{~g} / \mathrm{dl})$, RDW [14.3 (2.2) \%] and platelet $(244 \pm 87$ $\left.\times 10^{3} / \mu \mathrm{l}\right)$ levels. The study population showed racial diversity with relative (35\%) Hispanic preponderance.

After the diagnostic coronary angiography, 270 patients (53\%) were treated with medical therapy alone whereas the remaining 233 underwent either PCI ( $\mathrm{n}=$ $180 ; 36 \%)$ or CABG $(\mathrm{n}=53 ; 11 \%)$. Compared to the subjects undergoing medical therapy and PCI, respectively, patients requiring $\mathrm{CABG}$ were on average older $(70$ years vs. 63 and $68 ; \mathrm{p}<0.001$ ), less likely to have prior CABG (4 vs. 10 and $24 \% ; \mathrm{p}<0.001$ ) and had a higher prevalence of elevated RDW (30 vs. 21 and 15\%; $p=0.037$ ). Patients with CABG had a more extensive atherosclerotic burden (in terms of number of diseased vessels by catheterization findings). A higher prevalence of heart failure was noted in the CABG group compared to the other two (45 vs. 36 and $29 \%$, respectively) with borderline statistical significance $(\mathrm{p}=0.064)$. High RDW $(>16.3 \%)$ was associated with anemia (77 vs. $36 \% ; \mathrm{p}<0.001)$ and heart failure (50 vs. $31 \%$; $<<0.001$; table 2). The prevalence of a higher atherosclerotic burden was noted in the high RDW group compared to the normal one (32 and $20 \%$ vs. 27 and $17 \%$, respectively) but it reached only borderline statistical significance $(\mathrm{p}=0.066)$. Race did not show any statistically significant difference across the RDW or the outcome divides ( $\mathrm{p}=0.772$ and $\mathrm{p}=0.258$, respectively).

In multivariable logistic regression analyses and after adjusting for age, gender, race, hemoglobin, atherosclerotic burden, heart failure, smoking, family history of coronary artery disease and previous CABG, a high RDW was not found to be statistically significantly associated with either conservative management (noninvasive, i.e. medical treatment only) versus recourse to any form of revascularization [PCI or CABG; OR $=0.97(0.51-1.84) ; \mathrm{p}=$ 0.922] nor with discrimination between $\mathrm{PCI}$ and non-PCI approaches [OR $=0.67(0.36-1.25) ; \mathrm{p}=0.208]$. It was, however, found to be independently associated with recourse to $\mathrm{CABG}$ versus nonsurgical strategy [OR $=2.39$ (1.045.50); $\mathrm{p}=0.041]$. This finding was similar after excluding all patients who had undergone previous CABG (table 3). This association had a sensitivity of $30 \%$, a specificity of $81 \%$ and a negative predictive value of $91 \%$. Few patients had CRP, BNP, iron, ferritin, total iron-binding capacity and ejection fraction measurements performed for these variables to be properly tested in the regression analyses. 
Table 3. Multivariable logistic regression models for high RDW

\begin{tabular}{|c|c|c|}
\hline Outcome & OR $(95 \% \mathrm{CI})$ & $\mathrm{p}$ \\
\hline \multicolumn{3}{|c|}{ Medical Management } \\
\hline Unadjusted & $1.21(0.78-1.88)$ & 0.399 \\
\hline Adjusted $^{1}$ & $0.97(0.52-1.81)$ & 0.916 \\
\hline Adjusted $^{2}$ & $0.97(0.51-1.84)$ & 0.922 \\
\hline \multicolumn{3}{|l|}{ PCI } \\
\hline Unadjusted & $0.59(0.37-0.96)$ & 0.035 \\
\hline Adjusted $^{1}$ & $0.69(0.38-1.25)$ & 0.222 \\
\hline Adjusted $^{2}$ & $0.67(0.36-1.25)$ & 0.208 \\
\hline Adjusted $^{3}$ & $0.60(0.34-1.06)$ & 0.078 \\
\hline \multicolumn{3}{|l|}{ CABG } \\
\hline Unadjusted & $1.86(0.99-3.49)$ & 0.055 \\
\hline Adjusted $^{1}$ & $2.33(1.02-5.32)$ & 0.044 \\
\hline Adjusted $^{2}$ & $2.39(1.04-5.50)$ & 0.041 \\
\hline Adjusted $^{4}$ & $2.43(1.02-5.82)$ & 0.045 \\
\hline \multicolumn{3}{|c|}{$\mathrm{p}$ values $<0.05$ are in bold. } \\
\hline \multicolumn{3}{|c|}{${ }^{1}$ Adjusted for age, gender, race, atherosclerotic burden, ane } \\
\hline \multicolumn{3}{|c|}{ mia, heart failure, smoking, family history of coronary artery dis- } \\
\hline \multicolumn{3}{|c|}{ ease and previous $\mathrm{CABG}$. } \\
\hline \multicolumn{3}{|c|}{${ }^{2}$ Adjusted for age, gender, race, hemoglobin, atherosclerotic } \\
\hline \multirow{2}{*}{\multicolumn{3}{|c|}{$\begin{array}{l}\text { burden, heart failure, smoking, family history of coronary artery } \\
\text { disease and previous CABG. }\end{array}$}} \\
\hline & & \\
\hline \multirow{3}{*}{\multicolumn{3}{|c|}{$\begin{array}{l}{ }^{3} \text { Adjusted for age, gender, atherosclerotic burden, coronary } \\
\text { artery disease, dyslipidemia, family history of coronary artery } \\
\text { disease, previous CABG and diagnosis. } \\
{ }^{4} \mathrm{n}=431 \text { after excluding patients with previous CABG. Adjust- }\end{array}$}} \\
\hline & & \\
\hline & & \\
\hline${ }^{4} \mathrm{n}=431$ afte & ents with previous & G. Adjust- \\
\hline \multicolumn{3}{|c|}{$\begin{array}{l}\text { ed for age, gender, race, hemoglobin, atherosclerotic burden, heart } \\
\text { failure, smoking and family history of coronary artery disease. }\end{array}$} \\
\hline
\end{tabular}

\section{Discussion}

RDW reflects variability in the size of circulating red cells (anisocytosis) and is routinely reported by automated laboratory equipment for complete blood counts. Although its use had been limited to the narrowing of the differential diagnosis of anemia, mounting evidence suggests additional roles for this measurement. The present study demonstrated an independent association between high RDW on admission and recourse to CABG in patients presenting with UA or NSTEMI. We found this association to be independent of multiple potential confounding factors, such as anemia, heart failure, age, race and smoking. RDW did not demonstrate any statistically significant association with medical therapy alone or PCI. No deaths were reported in this study. The likely reason for this finding is the lower acuity of the selected patient population, which excluded STEMI and intensive care patients.

This study extends previous work on the role and impact of RDW. In an analysis of 15,852 adult participants in
NHANES III, Perlstein et al. [4] determined that higher RDW (with a median of 14.35 in the highest quintile) was associated with increased risk of all-cause mortality independently of CVD risk. Patel et al. [5] found similar results in a meta-analysis on older populations (aged 73.6-79.1 years). They noted a graded increased risk of death associated with higher RDW values. The RDW-mortality association occurred in all major demographic, disease and nutritional risk factor subgroups examined. Tonelli et al. [6] had similar conclusions regarding all-cause mortality but also with increased risk of coronary death/nonfatal myocardial infarction, new symptomatic heart failure and stroke. The relation of high RDW and greater CHD risk was also the main theme of the study conducted by Zalawadiya et al. [7]. An RDW level greater than the seventyfifth percentile in both anemic and nonanemic participants was a significant predictor of greater CHD risk. As for cardiovascular disease, a high RDW has been reported to be associated with worse prognosis in patients with heart failure, acute myocardial infarction and those referred for percutaneous coronary interventions [8-11]. The study by Lippi et al. [12] analyzed the RDW values on admission of patients presenting to the local emergency department for chest pain suggestive of acute coronary syndrome (ACS). They found that RDW levels were highly correlated with troponin T levels and an RDW greater than $14 \%$ had a clinical sensitivity and specificity for diagnosing ACS of 79 and 50\%, respectively. When combined, troponin $\mathrm{T}$ and RDW levels had a diagnostic sensitivity of $99 \%$. They concluded that RDW might be considered alongside other conventional cardiac markers for the risk stratification of ACS patients admitted to emergency departments.

Despite cumulative reports associating RDW and prognosis, the underlying biological mechanism for this relation remains unknown. Chronic subclinical inflammation is the most frequently hypothesized pathway as it is a well-established entity preceding de novo cardiovascular events and could adversely influence erythropoiesis by a variety of mechanisms, including direct myelosuppression of erythroid precursors, reducing renal erythropoietin production and the bioavailability of iron, increasing erythropoietin resistance in erythroid precursor cell lines, promoting cell apoptosis and RBC membrane deformability, factors that might increase anisocytosis [13]. It is less likely to be the case though as RDW was not found to be correlated with inflammatory markers such as CRP [14]. However, in patients with conditions characterized by increased levels of oxidative stress, such as Down syndrome, poor pulmonary function and dialysis, RDW values are elevated [15-17]. 
Decreased serum antioxidant levels, including carotenoids, selenium and vitamin E, were also associated with increased RDW [18]. An elevated RDW can also be a sign of 'reticuloendothelial block' or impaired iron metabolism that may directly contribute to disease progression [19]. It is conceivable that there are subclinical disease processes that cause a subtle dysregulation of erythrocyte homeostasis that is expressed in RDW.

Several limitations should be considered in the interpretation of the results. This study is a retrospective nonrandomized analysis and has inherent limitations of a retrospective design. Data on medication, previous admissions, as well as factors required for disease burden scoring (whether as separate variables or as a score) was not present in the medical records collected and information on ejection fraction, iron profile, CRP and BNP was not consistent enough to allow for a proper analysis of these factors. This was a single-center study of UA and NSTEMI patients only, a potential hindrance to external validity. Since the study population was fairly diverse from clinical and racial perspectives this study should have reasonable generalizability within the target population. Baseline characteristics between the RDW and outcome groups were reasonably similar, but certain differences, especially high-RDW patients having, for example, a higher prevalence of anemia and heart failure, had to be adjusted for. Despite adjustment for multiple variables and assessment of potential confounding factors and effect modifiers, residual unrecognized confounding variables could influence the observed differences in outcomes between the groups. As with all analyses of observational data, this study cannot distinguish causality from association. However, the hypothesis that elevated RDW measurements is associated with higher recourse to CABG (based on a review of the available literature in this regard) had been formulated before performing analyses on the database. This approach reduced the risk of spurious conclusions. Nevertheless, RDW was assessed on a single occasion (admission) that might be influenced by biologic variability or measurement error, although such errors are likely to attenuate the observed association between RDW and outcome. The cutoff value for high RDW differed from that of larger studies such as NHANES III, but it was consistent with the laboratory's range. The actual angiograms were not reviewed to verify the reported findings, especially among those with no (or nonobstructive) CAD. There was no standardized evaluation of atherosclerotic burden such as the SYNTAX score [20] as the required data was not available in the medical records at hand. The revascularization strategy (especially CABG) was at the discretion of the treating physician and depended on the patients' consent. The treating physician was also aware of the actual RDW value, introducing a potential bias to the results. However, in view of the retrospective nature of this investigation it is less likely to be the case. We also could not account for patients who were considered high risk for surgery as we did not have reliable means to assess nonatherosclerotic disease burden. These factors were a likely source of bias and may be the reason behind this relatively low frequency of CABG (11\%) for a tertiary care center. However, findings such as the marked prevalence of higher atherosclerotic burden and of heart failure in subjects undergoing CABG are consistent with the current recommendations [21] and therefore indicate a trend towards adherence to the established guidelines rather than personal or group practice behavior. Finally, this study does not provide a mechanism for the association between RDW and the observed outcome, but to date no biological pathway for RDW's role has been clearly established.

In conclusion this study has demonstrated an independent association of elevated RDW with recourse to CABG. These findings are concordant with, and extend, previous reports about the potential roles of RDW in patients with cardiovascular disease. Despite its low sensitivity but considering its high negative predictive value, its availability to clinicians as part of the complete blood count and lack of additional costs, RDW should be considered as a potential additional tool for stratification of patients presenting to emergency departments with UA or NSTEMI. A potential benefit from such early classification may be the successful avoidance of thienopyridine loading in patients who are more likely to be CABG candidates as this may incur a 5- to 7-day delay in surgery. In view of the retrospective, observational and chart abstraction design of this investigation further prospective studies are recommended to confirm the association between RDW and clinical outcomes and explain its underlying mechanism.

\section{Acknowledgments}

We would like to thank Steven R. Bergmann, MD, PhD, for his contribution to this article.

This publication was supported in part by the National Center for Research Resources (NCRR) and the National Center for Advancing Translational Sciences (NCATS), components of the National Institutes of Health (NIH), through CTSA grant numbers UL1RR025750, KL2RR025749 and TL1RR025748. Its contents are solely the responsibility of the authors and do not necessarily represent the official views of the NIH. 


\section{References}

$>1$ Evans TC, Jehle D: The red blood cell distribution width. J Emerg Med 1991;9(suppl 1):71-74.

-2 Looker AC, Gunter EW, Johnson CL: Methods to assess iron status in various NHANES surveys. Nutr Rev 1995;53:246-254.

3 Van hove L, Schisano T, Brace L: Anemia diagnosis, classification, and monitoring using Cell-Dyn Technology reviewed for the new millennium. Lab Hematol 2000;6:93-108.

$\checkmark 4$ Perlstein TS, Weuve J, Pfeffer MA, Beckman JA: Red blood cell distribution width and mortality risk in a community-based prospective cohort. Arch Intern Med 2009;169: 588-594.

$\checkmark 5$ Patel KV, Semba RD, Ferrucci, et al: Red cell distribution width and mortality in older adults: a meta-analysis. J Gerontol A Biol Sci Med Sci 2010;65:258-265.

6 Tonelli M, Arnold M, Moye L, et al: Relation between red blood cell distribution width and cardiovascular event rate in people with coronary disease. Circulation 2008;117:163168.

$>7$ Zalawadiya SK, Veeranna V, Niraj A, Afonso L: Red cell distribution width and risk of coronary heart disease events. Am J Cardiol 2010;106:988-993.

$>8$ Allen LA, Felker GM, Mehra MR, et al: Validation and potential mechanisms of red cell distribution width as a prognostic marker in heart failure. J Card Fail 2010;16:230-238. $\checkmark 9$ Dabbah S, Hammerman H, Markiewicz W, Aronson D: Relation between red cell distribution width and clinical outcomes after acute myocardial infarction. Am J Cardiol 2010;105:312-317.

10 Poludasu S, Marmur JD, Weedon J, Khan W Cavusoglu E: Red cell distribution width (RDW) as a predictor of long-term mortality in patients undergoing percutaneous coronary intervention. Thromb Haemost 2009; 102:581-587.

11 Cavusoglu E, Chopra V, Gupta A, Battala VR, Poludasu S, Eng C, Marmur JD: Relation between red blood cell distribution width (RDW) and all-cause mortality at two years in an unselected population referred for coronary angiography. Int J Cardiol 2010;141: 141-146.

12 Lippi G, Filippozzi L, Montagnana M, Salvagno GL, Franchini M, Guidi GC, Targher G: Clinical usefulness of measuring red blood cell distribution width on admission in patients with acute coronary syndromes. Clin Chem Lab Med 2009;47:353-357.

13 Weiss G, Goodnough LT: Anemia of chronic disease. N Engl JMed 2005;352:1011-1023.

14 Fukuta, Ohte N, Mukai S, Saeki T, Asada K, Wakami K, Kimura G: Elevated plasma levels of B-type natriuretic peptide but not Creactive protein are associated with higher red blood cell distribution width in patients with coronary artery disease. Int Heart J 2009;50:301-312.
15 Garcez ME, Peres W, Salvador M: Oxidative stress and hematologic and biochemical parameters in individuals with Down syndrome. Mayo Clin Proc 2005;80:1607-1611.

16 Grant BJ, Kudalkar DP, Muti P, et al: Relation between lung function and $\mathrm{RBC}$ distribution width in a population-based study. Chest 2003;124:494-500

17 Kobayashi S, Moriya H, Aso K, Ohtaka T: Vitamin E-bonded hemodialyzer improves atherosclerosis associated with a rheological improvement of circulating red blood cells. Kidney Int 2003;63:1881-1887.

18 Patel KV, Ferrucci L, Ershler WB, Longo DL, Guralnik JM: Red blood cell distribution width and the risk of death in middle-aged and older adults. Arch Intern Med 2009;169: 515-523.

19 Ganz T: Hepcidin, a key regulator of iron metabolism and mediator of anemia of inflammation. Blood 2003;102:783e8.

20 Serruys PW, Morice MC, Kappetein AP, et al: Percutaneous coronary intervention versus coronary-artery bypass grafting for severe coronary artery disease. N Engl J Med 2009; 360:961-972.

21 Hillis LD, Smith PK, Anderson JL, et al: 2011 ACCF/AHA Guideline for Coronary Artery Bypass Graft Surgery: executive summary: a report of the American College of Cardiology Foundation/American Heart Association Task Force on Practice Guidelines. Circulation 2011;124:2610-2642. 